\title{
Josef Breuer über seinen Anteil an der Psychoanalyse
}

\author{
Von Erwin H. Agkerknecht
}

Es ist wohlbekannt, daß in den Anfängen der Psychoanalyse Sigmund Freud in engster Zusammenarbeit mit dem 14 Jahre älteren namhaften Wiener Physiologen und Praktiker Josef Breuer stand, mit dem zusammen er 1895 die berühmten Studien über Hysterie veröffentlichte. Wie nahe auch ihre persönlichen Beziehungen waren, geht mit aller Deutlichkeit aus E. Jones großer Freud-Biographie hervor (London 1953), in der ein Kapitel des ersten Bandes «The Breuer Period (1882-1895)» betitelt ist.

Freud hat sich wiederholt und ziemlich verschiedenartig öffentlich (z.B. in seinen Vorlesungen an der Clark University, in seiner Geschichte der psychoanalytischen Bewegung, in seiner Selbstbiographie, im Nachruf für Breuer, posthum in seinen Briefen an W. Fließ) über Breuers Anteil an den gemeinsamen Entdeckungen geäußert. Seine Schüler sind ihm auf diesem Wege gefolgt. Soweit wir wissen, hat dies Breuer, seinem Wesen entsprechend, nie getan, ja isi geflissentlich Gelegenheiten dafür aus dem Wege gegangen (z. B. in seinem Curriculum vitae, Wien 1923, oder dem Vorwort zur Neuauflage der Studien). Für eine objektive Beurteilung der Sachlage scheint es aber unerläßlich, auch Breuer zu hören, um so mehr als Breuer eine bedeutende Persönlichkeit war, die mehr Aufmerksamkeit verdient, als sie bisher gefunden hat*.

Der folgende Brief Breuers an Auguste Fonel aus dem Jahre 1907, den ich in den reichen Sammlungen des Medizinhistorischen Instituts der Universität Zürich fand, macht dies endlich möglich.

\section{Hochverehrter Herr!}

Wien, 21/11 07

Die Bẻantwortung Ihres freundlichen Schreibens wurde einige Tage verzögert, weil ich das alte Buch (Studien über Hysterie) wieder durchsehen mußte, um meine Erinnerung aufzufrischen. Das ist nun geschehen und ich gestehe, daß ich, gegen meine Erwartung, recht zufrieden damit war. Was nun die Frage nach dem geistigen Eigentum an den verschiedenen Elementen der betr. Theorie u. der psychotherap. Analyse angeht, muß ich vor allem bemerken, daß ich darüber mit Freud nicht mich besprechen kann, weil jch seit Jahren außer aller persönlichen Beziehung zu ihm bin. Es ist aber sehr schwer bei so gemeinsamer Arbeit, wie jene in der das Buch entstanden ist, die Eigentumsrechte genau zu scheiden; rein aus der eigenen Erinnerung heraus. Ich hatte den Fall erlebt, den ich als

* Für einen ungenügenden Versuch in dieser Richtung siehe die These von J. J. TeplinsKy, Madison (Wis.) 1954. 
N. I. Anna O. in den Studien beschrieben habe. Mein Verdienst bestand wesentlich darin, daß ich erkannte, welch ungemein lehrreichen, wissenschaftlich wichtigen Fall mir der Zufall zur Bearbeitung zugewiesen hatte, daß ich in aufmerksamer treuer Beobachtung ausdauerte und nicht durch vorgefaßte Meinungen die einfache Auffassung des wichtigen Gegebenen störte. So habe ich damals sehr viel gelernt; viel wissenschaftlich wertvolles; aber auch das practisch wichtige, daß ein «general practitioner» unmöglich einen solchen Fall behandeln könne, ohne daß seine Tätigkeit $u$. Lebensführung völlig dadurch zerstört würde. Ich habe mir damals gelobt, noch einmal durch ein solches Ordal nicht zu schreiten. Als nun Fälle zu mir kamen, bei denen ich von analytischer Behandlg viel erwartete, die ich selbst aber nicht behandeln konnte, wies ich sie an Dr. Freud, der aus Paris u. der Salpetrière gekommen war, u. mit dem ich im intimsten freundschaftlichen $u$. wissenschaftlichen Verkehre $s^{+}$and. Die Krankheitsfälle, Verlauf, Behandlung u. was sich daraus für die Theorie ergab, wurden natürlich fortlaufend zwischen uns verhandelt; dabei wuchsen unsere theoretischen Anschauungen, nicht ohne Abweichungen natürlich, aber doch in so gemeinsamer Arbeit, daß es recht schwer ist, zu sagen was vom einen, was vom andern kam. Doch meine ich so viel sagen zu können:

Was direct aus dem Fall Anna O. folgt, ist von mir, also die aetiologische Bedeutung der, ihrer normalen Reaction beraubten, affectiven Vorstellung, welche dauernd als psychischer Fremdkörper wirkt; «Retentionshysterie»; die Anschauung von der Bedeutung der hypnoiden Zustände für die Entstehg der Hysterie; die analytische Therapie.

Was Phobien angeht, waren wir natürlich sehr geneigt, dieselbe Aetiologie zu vermuten; Freud war sehr erstaunt, als die Analysen oft ergebnislos blieben, aber immer häufiger u. sicherer sexuale Anomalien (coit. interrupt u. dgl.) als Ursache erkennbar wurden (Ich halte das für eine Entdeckg von der größten practischen Wichtigkeit).

Ebenso zweifelnd und erstaunt waren wir, als die Analysen schwerer Hysterien (bes. «Caecilie M.» des Buches) immer weiter in die Kindheit zurückführten; auch das waren natürlich nur Freud's Befunde.

Freud gehört durchaus die «Conversion der Affect-Erregung» u. die Lehre von der «Abwehrneurose» u. der überragenden Bedeutung der «Abwehr» für die Bildung «bewußtseinsunfähiger» Vorstellungscomplexe, aus denen die Spaltg der Psyche (double conscience) erwächst. Dem gegenüber verschwand ihm die pathologische Leistung der «hypnoiden Zustände»; wie ich glaube, nicht zum Vorteil der Lehre.

Ich habe in der Gemeinschaft mit Freud auch noch das Vordrängen des Sexualen beobachten können; u. ich kann versichern, daß es nicht einer Hinneigung zu diesem Thema entstammte, sondern ganz den, großenteils sehr unerwarteten Befunden der ärztlichen Erfahrung. Freud ist ein Mann der absoluten und exclu- 
siven Formulirungen; das ist ein psychisches Bedürfnis, das ihn - meiner Anschauung nach - zu übergroßen Generalisationen treibt. Dazu mag noch die Lust kommen, d'épâter le bourgeois. In der Hauptsache aber entstammen wie gesagt, seine Anschauungen darüber einfach der Erfahrung u. was darüber hinausgeht, erfüllt eben das Gesetz der Pendelschwingung, das alle Entwicklung beherrscht. Früher war alle Hysterie sexual, dann meinten wir unsere Kranken zu beschimpfen, wenn wir irgend ein sexuales Gefühl in ihre Aetiologie eingereiht hätten, und jetzt, nachdem der wirkliche Sachverhalt wieder zum Vorschein gekommen ist, schlägt das Pendel nach der andern Seite aus.

Daß eine schwere Hysterie ohne sexuale Basis entstehen, blühen $u$. sich lösen kann, beweist der Fall Anna O. der die Keimzelle der ganzen Psychoanalyse war. $\mathrm{Da} \beta$ dieses Eintauchen ins Sexuale in Theorie u. Praxis nicht mein Geschmack ist, gestehe ich. Aber was hat mein Geschmack u. meine Empfindung von passend u. unpassend mit der Frage zu tun: was ist?

Ich habe schon gesagt, daß ich persönlich mit F. ganz auseinander gekommen bin; und ganz schmerzlos war das natürlich nicht. Aber ich halte auch jetzt noch Freud's Werk für ein großartiges; in mühsamster Privatpraxis aufgebaut u. von der größten Wichtigkeit; wenn auch gewiß nicht weniges von dem Bau wieder abbröckeln wird.

Mit besten Empfehlungen

J. Breuer 